\title{
MAKNA SIMBOLIS RITUAL LEGHA KIWAN DALAM RITUS KELAS MASYARAKAT MANGGARAI TIMUR: KAJIAN ETNOLINGUISTIK
}

\author{
Fransiskus Opileoanus Sanjaya \\ Universitas Sanata Dharma Yogyakarta \\ ophyin.os@gmail.com
}

\begin{abstract}
ABSTRAK
Penelitian ini bertujuan mendeskripsikan makna simbolis yang terdapat dalam ritual legha kiwan pada ritus kelas mese atau kenduri masyarakat Manggarai Timur, Flores, NTT. Penelitian ini merupakan jenis penelitian kualitatif dengan nenerapkan prinsip-prinsip etnografi. Data dalam penelitian ini adalah cuplikan-cuplikan tururan dalam ritual legha kiwan. Sumber data penelitian ini adalah sumber data substantif dan sumber data lokasional. Sumber data substantif dalam penelitian ini adalah tuturan lisan dalam ritual legha kiwan yang sudah ditranskripsi menjadi teks. Sementara itu, sumber data lokasional dalam penelitian ini adalah wilayah Kabupaten Manggarai Timur. Adapun metode pengumpulan data yang digunakan adalah observasi partisipatif dan wawancara dengan teknik simak-rekam dan etnografi. Data yang terkumpul kemudian diklasifikasi dan tipifikasi sehingga terwujud tipe-tipe data yang siap dikenai teknik analisis data. Data dalam penelitian dianalisis menggunakan metode padan ekstralingual dengan teknik analisis data kontekstual. Ada tiga tahapan dalam menganalisis data, yaitu identifikasi, klasifikasi, dan interpretasi. Berdasarkan hasil analisis data diketahui bahwa ritual legha kiwan mengandung makna simbolis penghormatan, kerja keras, cinta kasih, kepandaian, dan pengaharapan.
\end{abstract}

Kata kunci: etnolinguistik; legha kiwan; makna simbolis; Manggarai Timur

\begin{abstract}
This study aims to describe the symbolic meaning contained in the legha kiwan ritual in the mese class rites or feasts of the people of East Manggarai, Flores, NTT. This research is a type of qualitative research by applying ethnographic principles. The data in this study are snippets of tururan in the legha kiwan ritual. The data sources of this research are substantive data sources and local data sources. The source of substantive data in this study is oral speech in the legha kiwan ritual which has been transcribed into text. Meanwhile, the source of locational data in this study was the East Manggarai Regency area. The data collection methods used were participatory observation and interviews with the watch-record technique and ethnography. The collected data is then classified and typified so that data types are ready to be subjected to data analysis techniques. The data in the study were analyzed using the extralingual equivalent method with contextual data analysis techniques. There are three stages in analyzing data, namely identification, classification, and interpretation. Based on the results of data analysis, it is known that the legha kiwan ritual contains symbolic meanings of respect, hard work, love, intelligence, and hope.
\end{abstract}

Keywords: ethnolinguistic; legha kiwan; symbolic meaning; East Manggarai

\section{PENDAHULUAN}

Kajian tentang kearifan-kearifan lokal di wilayah NTT, khususnya etnis Manggarai masih terus dilakukan. Hal ini dilakukan karena masyarakat etnis Manggarai kaya akan budaya lokal dan nilai-nilai kebudayaan lokal yang dimiliki dapat bersifat local indigenious.
Keaslian budaya yang dimiliki kemudian perlu dipelihara dan dilestarikan, salah satunya melalui kajian-kajian ilmiah.

Ritus kelas merupakan salah satu kebudayaan asli masyarakat Manggarai yang masih dilaksanakan sebagai wujud 
penghormatan terhadap leluhur. Kelas yang bararti "kenduri" dalam bahasa Indonesia adalah acara/pesta perpisahan dengan roh/jiwa orang yang meninggal. Jiwa/roh dari orang yang meninggal disucikan dan diselamatkan melalui ritus kelas. Menurut kepercayaan orang Manggarai, apabila ritus kelas belum dilaksanakan, maka jiwa/roh dari orang yang meninggal akan terus bergentayangan.

Ritus kelas di Manggarai Timur digolongkan menjadi dua, yaitu kelas dan kelas mese. Kelas adalah kenduri yang dilaksanakan secara sederhana dan hewan persembahannya adalah babi, kuda, atau sapi, sedangkan kelas mese adalah kenduri yang dilaksanakan secara besar-besaran; melibatkan banyak orang dan hewan kurbannya adalah kerbau (Robot et al., 1996). Berdasarkan tempat pelaksanaanya, kelas mese dilaksanakan di natas atau halaman kampung, sedangkan kelas dilaksanakan di depan rumah. Berdasarkan jumlah jiwa/roh orang meninggal yang ingin di-kelas-kan, dalam ritus kelas mese berjumlah 4-5 orang, sedangkan dalam kelas biasanya hanya satu orang.

Dalam ritus kelas masyarakat Manggarai Timur terdapat salah satu ritual yang diberi nama legha kiwan. Dalam bahasa Manggarai Timur dialek Tok, istilah legha kiwan berasal dari kata legha dan kiwan. Kata legha artinya "selang (waktu, peristiwa, ruang)" dan kiwan artinya "tahun". Dengan demikian, legha kiwan berarti selang tahun. Ritual legha kiwan dilaksanakan tiap tahun untuk menyambut tahun yang baru, secara khusus untuk menyambut musim tanam baru. Jadi, melalui ritual legha kiwan musim tanam di tahun sebelumnya ditinggalkan, dan masyarakat siap menyambut musim tanam yang baru di tahun yang baru. Bagi masyarakat Manggarai Timur, ritual legha kiwan wajib dilaksanakan dalam kelas, karena sudah diturunkan dan diwariskan dari leluhur. Ritus kelas boleh dilaksanakan setelah melaksanakan ritual legha kiwan. Kepercayaan masyarakat Manggarai Timur, apabila ritual legha kiwan belum dilaksanakan, maka kelas yang akan dilaksanakan tidak diterima oleh leluhur. Masyarakat Manggarai Timur menyampaikan syukur kepada Tuhan dan leluhur atas musim tanam di tahun sebelumnya, dan memohon berkat dari Tuhan dan leluhur untuk musim tanam di tahun yang baru melalui ritual legha kiwan.

Sebagai ritual khas, dalam ritual legha kiwan terdapat kearifan-kearifan lokal, baik yang berwujud nyata (tangible) maupun yang berwujud tidak nyata (intangible) (PDSPK, 2016). Kearifan lokal tangible berupa benda, yakni peranti-peranti adat dalam ritual tersebut, sedangkan kearifan lokal intangible berupa kata-kata, yaitu istilah-istilah adat, ungkapanungkapan adat, dan doa-doa khas dalam ritual tersebut. Berkaitan dengan hal itu, ketika peneliti menyimak tuturan-tuturan dalam ritual legha kiwan berupa istilah-istilah, ungkapanungkapan, doa-doa, atau mengamati bendabenda adat dalam ritual legha kiwan, peneliti selalu dihadapkan dengan pertanyaan "apa maksudnya?" atau "apa makna yang tersembunyi dibalik tuturan atau benda-benda adat itu?". Peneliti meyakini bahwa dalam ritual legha kiwan terkandung makna-makna simbolis yang dijadikan landasan dan pedoman hidup masyarakat Manggarai Timur. Sebagaimana dijelaskan bahwa menurut keyakinan orang Manggarai, seluruh tatanan kehidupan manusia diramu di dalam simbolsimbol, baik di alam hubungan antara sesama manusia dengan alam maupun dengan dunia adikodrati (Deki, 2011: 56). Simbol-simbol itu memiliki nilai sakral dan dihargai oleh seluruh anggota persekutuan komunal. Simbol-simbol itu menyentuh eksistensi mereka dan menentukan keberlangsungan hubungan mereka dengan sesama, alam dunia dan adikodrati. Oleh karena itu, untuk menjawab pertanyaan di atas perlu diketahui konsep makna simbolis sebagai landasan dalam penelitian ini.

Simbol adalah sesuatu yang mewakili susuatu yang lain berdasarkan hubungan analaogi (Eco, 1984: 130). Sebuah simbol mewakili referensi dengan cara konvensional (Danesi, 2004). Jadi, simbol adalah sesuatu yang menunjukkan, mewakili atau memberi kesan mengenai sesuatu yang lain. Simbolsimbol tersebut dapat berwujud objek fisik (benda kasat mata), kata-kata (untuk mewakili objek fisik, perasaan, ide, dan nilai), serta tindakan (yang dilakukan orang untuk memberi arti dalam berkomunikasi dengan orang lain) (Ahmadi, 2005). Menurut Firth (1973, dalam Eco, 1984:132), gerakan simbolik tidak 
berusaha mendapatkan efek konkret langsung. Firth memperhatikan jaringan hubungan kontras: dari konkret ke abstrak, dari abstrak ke konkret, dan dari metafora yang tidak jelas (semu, ambigu); pada tingkat pertama juga bisa menjadi konvensional. Tentunya, simbolisme tuturan dan benda-benda adat dalam ritual legha kiwan sejalan dengan jaringan hubungan kontras menurut Firth.

Pandangan, pengetahuan, dan kemampuan manusia untuk mempelajari dunia bervariasi. Variasi ini menentukan sebelumnya berbagai pemahaman teliti tentang sifat dan makna simbol (Zhirenov et al., 2016). Dengan demikian, makna benda atau simbol berdiri tidak stagnan. Orang, masyarakat, dan dunia terus berubah. Begitu juga makna itu senadiri, makna tidak melekat, tetapi disusun oleh interaksi individu, objek, dan konteks. Makna, oleh karena itu, berbeda antara individu dan situasi untuk individu yang sama (Lemon, 2003). Oleh karena itu, kajian makna simbolis bahasa sangat bergantung pada konteks ((Yule, 2014) Konteks adalah segala sesuatu yang berada di luar teks (tetapi melingkupi) tetapi melingkupi teks yang sedang dibahas (Pranowo, 2014). Konteks digolongkan ke dalam tiga jenis, yaitu konteks linguistik, konteks situasional, dan konteks budaya (Pranowo, 2014; Song, 2010). Berkaitan dengan konteks penelitian ini, konteks yang paling berpengaruh adalah konteks sosial dan budaya. Konteks sosial dan budaya adalah halhal yang timbul sebagai akibat dari munculnya interaksi antaranggota masyarakat dalam budaya tertentu (Pranowo dan Neneng Tia, 2019). Konteks dalam penelitian ini digunakan untuk menemukan makna linguistik.

Adapun masalah yang melatarbelakangi penelitian ini berdasarkan hasil pengamatan empiris peneliti, yaitu (1) keterlibatan kaum muda dalam ritus/ritual sakral magis dan statis ini minim; (2) akibat keterlibatan kaum muda dalam ritus ini minim, pewarisan tata cara adat dan nilai-nilai budaya terbatas pada orang tua (orang tua sebutan untuk usia 45 tahun ke atas); (3) interferensi bahasa Indonesia dalam ritus ini mulai tampak. Kondisi ini menyebabkan lunturnya keaslian bahasa daerah. Jadi, alasanalasan di atas mendorong peneliti melakukan kajian ini guna melestarikan makna simbolis riual legha kiwan. Selain itu, penelitian ini dilakukan sebagai upaya pencatatan, sehingga generasi yang akan datang masih dapat marasakan dan menikmati anugerah kebudayaan masyarakat Manggarai Timur.

Apabila seseorang ingin mencari makna simbolis bahasa dari etnis tertentu, ia juga perlu pemahaman tentang etnolinguistik. Etnolinguistik adalah bidang linguistik antropologi yang berhubungan dengan studi bahasa dari etnis tertentu dan hubungan antara bahasa dan budaya (collinsdictionary.com). Foley mengungkapkan bahwa etnolinguitik merupakan cabang ilmu linguistik yang berkaitan dengan posisi bahasa dalam konteks sosial dan budaya untuk mempromosikan dan mempertahankan praktek budaya dan struktur sosial (Foley, 1997). Menurut Riley etnolinguistik telah didekati dengan berbagai cara sebagai studi tentang pengalaman hidup kelompok yang diorganisir dan diekspresikan melalui alat bahasa kelompok dan sebagai ilmu yang bertujuan untuk memeriksa hubungan antara bahasa di satu sisi dan masyarakat dan budaya di sisi lain (Riley, 2007). Selanjutnya, Riley menegaskan, bidang utama etnolinguistik meliputi hubungan antara bahasa dan budaya, praktik dan komunikatif, dan model kognitif bahasa dan pemikiran (Riley, 2007).

Berdasarkan uraian itu, tujuan penelitian ini adalah mendeskripsikan makna simbolis ritual legha kiwan pada ritus kelas mese masyarakat Manggarai Timur dapat berkontribusi terhadap pengembangan bahasa Indonesia. Selain itu, semoga penelitian ini berkontribusi terhadap pelestarian nilai-nilai budaya yang mulai terkikis akibat perkembangan zaman.

\section{METODE}

Penelitian ini merupakan jenis penelitian kualitatif (Creswell, 2010). Sumber data penelitian ini adalah sumber data substantif dan sumber data lokasional. Sumber data substantif dalam penelitian ini adalah tuturan lisan dalam ritual legha kiwan yang sudah ditranskripsi menjadi teks. Sementara itu, sumber data lokasional dalam penelitian ini adalah wilayah Kabupaten Manggarai Timur. Data penelitian ini adalah cuplikan-cuplikan tuturan lisan dalam ritual legha kiwan. Objek penelitian yaitu makna-makna simbolis. Data dikumpul menggunakan metode observasi dan wawancara dengan teknik pengumpulan data 
simak rekam (Sudaryanto, 2015) dan etnografi komunikasi (Spradley, 2007:63). Observasi dilakukan dalam ritual legha kiwan, sedangkan metode wawancara dilakukan terhadap tokoh adat dan orang tua yang mempunyai pengetahuan mengenai ritual legha kiwan di kampung Tok. Wawancara ini dilakukan sekaligus untuk memvalidasi data yang telah dikumpulkan dan dianalisis. Pengumpulan data juga didukung melalui rekaman audio dan video untuk mendukung hasil observasi jika ada data yang terlupakan ketika melakukan observasi. Instrumen penelitian adalah peneliti sendiri dengan bekal pemahaman bahasa dan budaya Manggarai Timur, dan teori kajian etnolinguistik.

Setelah semua data terkumpul, selanjutnya data diklasifikasi dan tipifikasi sehingga terwujud tipe-tipe data yang siap dikenai metode dan teknik analisis data. Adapun teknik analisis data yang digunakan dalam penelitian ini adalah padan ekstralingual. Metode padan ekstralingual ini digunakan untuk menganalisis unsur yang bersifat ekstralingual, seperti menghubungkan masalah bahasa dengan hal yang berada di luar bahasa (Mahsun, 2012). Selaras dengan itu, teknik analisis data yang digunakan dalam penelitian ini adalah teknik analisis data kontekstual. Teknik analisis data kontekstual adalah cara analisis yang diterapkan pada data dengan mendasarkan dan mengaitkan konteks (Rahardi, 2009). Analisis data ditempuh peneliti melalui tiga tahapan, yaitu (1) mengidentifikasi data untuk menemukan ciri penanda khas yang berkaitan dengan wujud simbol dalam ritual legha kiwan, (2) mengklasifikasi data yang berkaitan dengan simbol dalam ritual legha kiwan, dan (3) menginterpretasi makna simbolis.

\section{PEMBAHASAN}

Berdasarkan hasil analisis data ditemukan bahwa terdapat lima makna simbolis dalam ritual legha kiwan yaitu penghormatan, kerja keras, cinta kasih, kepandaian, dan pengaharapan. Makna-makna tersebut diuraikan secara rinci pada subbagian berikut.

\section{Makna Penghormatan}

Penghormatan merupakan salah satu makna simbolis yang terdapat dalam ritual legha kiwan. Penghormatan berasal dari kata dasar "hormat" yang berarti (1) menghargai (takzim, khidmat, sopan), (2) perbuatan yang menandakan rasa khidmat atau takzim (seperti menyembah, menunduk). Sementara itu, penghormatan adalah proses, cara, perbuatan menghormati; pemberian hormat (Kamus Besar Bahasa Indonesia, 2019). Pengertian tersebut memberi pehaman bahwa penghormatan merujuk pada persaan dan sikap seseorang terhadap orang lain. Hal ini bermakna penghormatan adalah proses memberi rasa hormat, bukan menerima rasa hormat. Dalam tuturan adat legha kiwan makna penghormatan terlihat melalui salah satu contoh data di bawah ini, baik secara implisit maupun eksplisit. Berikut adalah contoh data yang menunjukkan hal tersebut.

Yo ite kamping keta Ema Teno laku liut tombo neki de dite wone mai wie gho'o ai wero laku ite poli tombo laku kamping ite landing kap ngaraolon ede tombo olon tura de kamping wura baro de kamping seki wone mai wakar ede ase kae ulu le para sili beo Teong nggitu kole wura agu seki wone mai beo agu wae ramba na'a wa diding ata mangan teti kole ata werun ramba pesa kole beber rasan kole kope toe mu'un kanan laku tombo kamping ite gho tuak kepok.

(Yo engkau khusus kepada Bapa Teno saya sampaikan maksud pembicaraan dan kehadiran kita pada malam ini tadi sudah saya sampaikan kepada Bapak supaya terus berlanjutnya pembicaraan dulu permohonan kepada roh leluhur disampaikan kepada roh leluhur di dalam arwahnya keluarga inti di utara pintu di selatan kampung Teong begitu juga orang yang telah meninggal di dalam kampung dan air supaya simpan di bawah semua yang lama angkat lagi yang baru supaya siapkan kembali alat bekerja asa lagi parang bukan dengan mulut saja saya sampaikan kepada Bapak ini tuak kepok)

\section{Konteks:}

Tuturan disampaikan kepada Tua Teno sebelum legha kiwan dimulai. Tuturan disampaikan oleh juru bicara sambil memegang sebotol tuak. Tua Teno telah hadir bersama keluarga untuk melaksanakan ritual legha kiwan. Tua Teno adalah pemangku kepentingan 
yang mempunyai fungsi dan tugas mengatur hak dan kewajiban dalam hal pembagian; kepemilikan tanah ulayat/lingko di kampung Tok.

Tuturan pada data di atas menggambarkan penghormatan keluarga (diwakili oleh juru bicara) terhadap tua teno sebagai pemangku kepentingan di wilayah yang bersangkutan. Penghormatan terhadap tua teno tergambar jelas melalui konteks tuturan di atas bahwa tuturan disampaikan sebelum ritual legha kiwan dimulai. Berdasarkan hasil percakapan etnografi diketahui bahwa dalam sistem adat Manggarai, tiap tamu yang hadir wajib diberi salam secara adat dan salam pertama disampaikan kepada seseorang yang memiliki pangkat paling tinggi. Hal yang sama juga dijumpai dalam kegiatan formal masyarakat secara umum bahwa ketika memberi sambutan, misalnya dalam seminar atau pertemuan, penyambut selalu membuka sambutan dengan memberi salam dan salam pertama diberikan kepada seseorang yang memiliki pangkat paling tinggi, misalnya rektor lalu diikuti salam kepada dekan. Hal ini sejalan dengan konteks ritual legha kiwan yang diteliti bahwa tamu yang menyandang pangkat tertinggi dalam ritual legha kiwan yang bersangkutan adalah tua teno. Oleh karena itu, kehadiran tua teno bersama keluarga perlu diberi penghormatan. Hal ini sejalan pendapat Ahmadi (2008) bahwa salah satu wujud simbol adalah tindakan (yang dilakukan orang untuk memberi arti dalam berkomunikasi dengan orang lain).

Makna penghormatan pada tuturan di atas semakin jelas melalui sapaan yo ite kamping keta ema teno laku liut tombo 'yo engkau khusus kepada bapa teno saya sampaikan'. Ite merupakan sapaan terhormat kepada lawan bicara ketika berkomunikasi dalam masyarakat Manggarai (Timur). Kemudian, kata keta yang berarti 'khusus' pada tuturan di atas bermakna bahwa penghormatan itu patut diberikan kepada tua teno. Berdasarkan hasil percakapan etnografi, selain memberi penghormatan, tuturan di atas bermaksud meminta dukungan tua teno untuk kesuksesan ritual leghwa kiwan. Sementara itu, makna penghormatan pada tuturan di atas ditandai melalui kata kepok di akhir tuturan dan wujud dari penghormatan adalah sebotol tuak sebagaimana terdapat ungkapan toe muun kanan laku tombo kamping ite ghoo tuak kepok 'bukan dengan mulu saja saya sampaikan kepada engkau ini tuak kepok'. Tuak adalah peranti khas dalam ritual adat Manggarai. Tuak melampaui wujud benda. Tuak adalah simbol penghormatan yang tidak dapat diungkapkan melalui kata-kata. Berdasarkan hasil percakapan etnografi, sifat tuak yang alami; jernih; sejuk melambangkan ketulusan, sehingga tuak selalu digunakan dalam komunikasi adat masyarakat Manggarai. Hal ini sejalan dengan salah satu gerakan simbolik menurut Firth, yaitu dari konkret ke abstrak (Eco, 1984:132). Berkaitan dengan makna tuak, peneliti terdahulu juga menyatakan bahwa tuak yaitu minuman beralkohol yang dibuat dari nira aren yang diragikan melambangkan kesejukan bagi masyarakat Manggarai. Tuak digunakan sebagai media komunikasi dalam upacara adat Manggarai (Rahardi, Sanjaya \& Nurfatimah, 2020: p. 9). Dengan demikian, sangat jelas bahwa tuturan pada data di atas bermakna penghormatan.

Sapaan ite 'engkau' selalu digunakan dalam komunikasi adat Manggarai, bahkan digunakan dalam keseharian masyarakat Manggarai. Biasanya, ite digunakan untuk menyapa orang yang lebih tua dan sebaya. Seseorang yang menggunakan sapaan ite dalam berkomunikasi akan dikenal sebagai seseorang yang santun dalam berkomunikasi. Sementara itu, tuturan toe muun kanan laku tombo kamping ite ghoo tuak kepok 'bukan dengan mulut saja saya sampaikan kepada engkau ini tuak kepok' selalu digunakan sebagai kalimat penutup pesan yang disampaikan oleh juru bicara dalam acara adat apa pun di Manggarai. Adat masyarakat Manggarai sudah mengatur demikian dan kebiasaan itu diwariskan turuntemurun dari nenek moyang. Bahkan, penggunaan peranti tuak sebagai media komunikasi juga terjadi dalam kehidupan sehari-hari masyarakat Manggarai ketika ingin memohon bantuan kepada seseorang. Biasanya, ketika seseorang ingin meminjam uang atau meminta pekerjaan. Berdasarkan hasil percakapan etnografi, di dalam tuak terkandung ketulusan seseorang dan ketulusan itu tidak bisa diungkapkan melalui kata-kata, sehingga disimbolkan melalui tuak. Dengan demikian, sangat jelas bahwa dalam ritual leghwa kiwan terdapat makna penghormatan dan 
penghormatan itu tulus adanya yang diwujudkan melalui tuak.

\section{Makna Kerja Keras}

Kerja keras merupakan salah satu makna simbolis yang terdapat dalam ritual legha kiwan. Kerja keras merupakan salah satu karakter yang perlu ditanamkan dalam diri seseorang, karena dengan kerja keras cita-cita dan tujuan hidup akan tercapai (lihat Handayani \& Sumaryati, 2014; Suryanto dkk, 2017). Oleh karena itu, manusia harus bekerja keras dalam bidang yang ditekuni. Pekerjaan yang dikerjakan tidak mungkin berhasil maksimal jika manusia bermalas-malasan atau tidak mau bekerja keras. Manusia tidak akan menuai panenan yang berlimpah; manusia akan jauh ketinggalan dengan sesamanya jika tidak memiliki semangat kerja keras. Dalam tuturan adat ritual legha kiwan, makna kerja keras terlihat dalam cuplikan ramba na'a wa diding ata mangan teti kole ata werun ramba pesa kole beber rasan kole kope "supaya simpan di bawah semua yang lama, angkat lagi yang baru supaya siapkan kembali alat bekerja asa lagi parang'. Secara eksplisit, tuturan ini menggambarkan tujuan dari ritual legha kiwan, yakni menyambut tahun yang baru, khususnya musim tanam baru. Namun, secara implisit cuplikan tuturan di atas bermakna kerja keras yang ditandai melalui kata kope 'parang'. Kata kope yang berarti 'parang' dalam tuturan di atas merupakan simbol 'bekerja' bagi masyarakat Manggarai Timur. Masyarakat Manggarai Timur yang bermatapencarian sebagai petani tentu membutuhkan kope atau parang untuk bekerja. Kope digunakan untuk menebang kayu atau membersihkan ladang dari hama sehingga tanaman dapat tumbuh subur. Dengan kope masyarakat Manggarai Timur memulai segalanya: membuka ladang, menanam, dan memanen. Kope atau parang menggugah semangat masyarakat Manggarai Timur untuk bekerja, sehingga dalam keseharian terdapat pernyataan yang sering diucapkan orang tua kepada anak yang malas bekerja eme ete ata tua ndong kope meu kole wuli 'jika melihat orang tua pegang parang kalian juga bergerak'. Pernyataan tersebut bermaksud mengajak anak agar terlibat dalam pekerjaan orang tua mengurus ladang dan menggugah semangat anak untuk bekerja. Dengan demikian, sangat jelas bahwa dalam ritual legha kiwan juga terdapat makna simbolis kerja keras. Hal ini sejalan dengan gerakan simbolis menurut Firth (1973, dalam Eco, 1984:132), yaitu konkret ke abstrak.

\section{Makna Cinta Kasih}

Cinta kasih merupakan salah satu makna simbolis yang terdapat dalam ritual legha kiwan. Cinta kasih adalah salah satu kebutuhan hidup manusia yang cukup fundamental (Sugiyono, 2017). Makna simbolis cinta kasih dalam ritual legha kiwan terlihat dalam terminologi anak rona dan anak wina. Berkaitan dengan itu, legha kiwan merupakan salah satu tahapan acara yang dilaksanakan satu hari sebelum acara inti (kelas) dan dilaksanakan oleh anak rona. Anak rona yang dimaksud adalah anak rona ulu (saudara kandung) dan anak rona sapo alo likan lima (saudara sepupu). Keutamaan anak rona dalam ritual legha kiwan tidak bermaksud mensubordinasikan anak wina, melainkan karena adat sudah bijaksana mengatur secara demikian. Tata cara adat ini pun merupakan warisan dari leluhur. Namun bukan berarti anak wina tidak terlibat. Keterlibatan anak wina diwujudkan dalam sida yang bermakna ringan sama dijinjing berat sama dipikul. Hal ini berarti anak wina memberi bantuan berupa ayam, kambing, kuda, sapi, kerbau; dan uang (dengan angka yang telah ditentukan) kemudian diserahkan waktu acara inti (kelas) dilaksanakan. Begitu pula keterlibatan anak rona diwujudkan dalam hewan (babi) dan beras. Keutamaan anak rona karena anak rona dianggap sebagai "pegut ulu dekut wuwung" yang berarti "pelindung dan pemberi berkat" bagi anak wina. Hal ini sejalan dengan Widyawati (2017) bahwa anak rona sering dilihat sebagai sumber hidup dan sumber berkat bagi anak wina. Dengan demikian, sebelum ritual legha kiwan dilaksanakan pemilik acara legha kiwan wajib memberi kepok kepada anak rona yang hadir sebagai tanda penghargaan sekaligus memohon dukungan terselenggaranya acara kelas. Perlu diketahui, dalam siste pernikahan adat Manggarai, anak rona adalah sebutan untuk pihak pemberi istri, sedangkan anak wina sebutan untuk pihak penerima istri.

Berdasarkan uraian di atas maka cinta kasih bermakna memberi, bukan menerima. 
Pemberian merupakan ungkapan paling tinggi dari kemampuan. Hal paling penting dari memberi adalah ialah hal-hal yang sifatnya manusiawi, bukan materi. Berkaitan dengan konteks legha kiwan, keterlibatan akan rona dan anak wina didasari oleh rasa cinta kasih. Unsur dasar cinta kasih yag dinyatakan melalui istilah anak rona dan anak wina adalah tanggung jawab, yakni suatu tindakan yang sama sekali sukarela dalam hubungan orang tua dan anak; anak dan anak. Dalam konteks ini, anak (anak rona dan anak wina) mempunyai tanggung jawab bersama untuk meng-kelas-kan orang tuanya yang telah meninggal.

Anak rona ulu pada kutipan di atas disimbolkan dengan sapo agu likan, sedangkan anak rona di luar anak rona ulu disimbolkan dengan sapo alo likan lima. Sebagaiamna terdapat dalam kutipan lawang ende agu ema sapo agu likan beo Lena agu sanggen taung ngasang ede likan lima sapo alo ata res baling kele ras baling rasat ede ende agu ema sapo agu likan, wone tana beo Teong ata mberek agu neki wone mai wie gho'o 'semua mama dan bapa tungku api dan batu tungku kampung Lena dan semua nama dari tungku lima, batu tungku delapan yang rapat dekat ketiak mengapit dekat rusuknya mama dan bapa tungku api, dalam tanah kampung Teong yang duduk bersama pada malam ini'. Secara harafiah, sapo agu likan berarti 'tungku api dan batu tungku' dan lima dan alo berarti 'lima' dan 'delapan'. Sapo agu likan sumber kehidupan bagi masyarakat Manggarai. Sapo adalah salah satu bagian utama dari rumah orang Manggarai yang digunakan sebagai tempat untuk memasak makanan. Hal ini sejalan dengan Domino bahwa sapo adalah tungku api tempat memasak nasi dan air serta sumber kehangatan (Domino, 2015). Tanpa sapo agu likan masyarakat Manggarai tidak bisa masak untuk melangsungkan hidup. Dengan demikian, anak rona ulu (saudara kandung) diibaratkan dengan sapo agu likan sebagai sumber hidup dan berkat bagi anak wina (saudari). Kehidupan seorang saudari tidak dapat berjalan baik tanpa berkat dari saudari laki-laki. Hal ini sejalan dengan Helmon (2020:119 - 120) bahwa metafora ini berkaitan dengan fakta sejarah bahwa dulunya masyarakat Manggarai tidak bisa tanpa adanya tungku dan batu tungku. Kehidupan dari seorang saudari tidak dapat berjalan baik tanpa adanya berkat dari saudari laki-laki, sama seperti kehidupan keluarga tanpa adanya tungku dan batu tungku.

Ritual leghwa kiwan dan ritus kelas juga tidak terlepas dari dukungan sapo alo likan lima (saudara sepupu) yang res baling kele ras baling rasat ede ende agu ema sapo agu likan , artinya saudara sepupu yang bersatu dengan saudara kandung (di kampung Teong). Dalam acara adat apapun, saudara kandung dan saudara sepupu harus bersatu yang ditandai melalui kata ras yang berarti 'rapat' dan res berarti 'mengapit'. Hal ini barmakna bahwa dukungan dan berkat dari anak rona ulu akan semakin kuat apabila ada dukungan dari anak rona sapo alo likan lima. Berdasarkan hal tersebut, unsur dasar cinta kasih yang dinyatakan melalui istilah sapo agu likan dan sapo alo likan lima dalam ritual legha kiwan adalah keterikatan, yakni adanya rasa kebersamaan. Pelaksanaan ritus kelas akan terwujud apabila keluarga saling bahumembahu.

\section{Makna Kepandaian}

Kepandaian merupakan salah satu makna simbolis yang terdapat dalam ritual leghwa kiwan. Kepandaian berasal dari kata "pandai" yang berarti (1) cepat menangkap pelajaran dan mengerti sesuatu; pintar; cerdas; (2) mahir; cakap; terampil; (3) dapat; sanggup; (4) berilmu (KBBI V). Kata "pandai" mengalami konfiksasi menjadi "kepandaian" yang bermakna keadaan (perihal) pandai; kepintaran; kemahiran; kecakapan. Sebutan "pandai" dalam konteks ini diberikan kepada pelaku torok. Kesuksesan ritual legha kiwan tidak terlepas dari peran penting seorang pelaku torok. Torok adalah ungkapan-ungkapan yang tersusun dalam syair-syair indah untuk menyatakan maksud-maksud tertentu dan ditujukan kepada wujud tertinggi atau pun leluhur. Torok selalu disampaikan dalam konteks upacara adat, dalam suasana sakral, dan penutur merupakan representan dari peserta yang hadir. Torok kerap pula disebut sebagai doa asli orang Manggarai (Deki, 2011). Oleh karena itu, torok hanya dapat dilakukan oleh orang tertentu, yang tahu dan mampu melakukan torok. Orang yang tahu dan mampu melakukan torok manuk dan torok ela dianggap 
sebagai muun lujur lema emas sebagaimana pada terdapat pada cuplikan data berikut:

Yo ite ende ema ai ite ata mun lujur lema emas ite ata ghaeng tae regeng pede senggen goet de no'e mbate dise ame redong dise empo ai ite ata tombon ngaraolon a ede legha kiwan gho'o tuak botol pele tombon kepok

(Yo engkau mama bapa karena engkau yang mulut halus lida emas engkau yang tahu menyampaikan tahu pesan semua ungkapan dari warisannya bapa warisan para leluhur karena engkau yang menyampaikan ke depannya acara legha kiwan ini tuak botol untuk menyampaikannya kepok)

\section{Konteks:}

Tuturan ini disampaikan kepada pelaku torok manuk dan ela sebelum ritual legha kiwan dimulai. Tuturan ini bermaksud memohon kesediaan pelaku torok manuk dan ela untuk melakukan torok menyampaikan syukur dan pemhohonan kepada Tuhan dan leluhur melalui ayam dan babi sebagai persembahan. Tuturan ini disampaikan oleh juru bicara kepada pelaku torok.

Ungkapan muun lujur lema emas 'mulut halus lidah emas' pada kutipan di atas adalah kiasan bagi orang yang pandai. Berkaitan dengan ritual legha kiwan, pelaku torok dianggap sebagai orang yang pandai menyampaikan torok. Oleh karena itu, keluarga penyelenggara legha kiwan perlu memohon kerendahan hati pelaku torok agar bersedia melakukan torok. Wujud penghargaan terhadap pelaku torok ditandai melalui kata kepok. Sementara itu, tuak dalam kutipan di atas merupakan wujud pernghargaan keluarga terhadap roh leluhur sebagaimana pada kalimat ghoo tuak botol pele tombon 'ini tuak botol untuk menyampaikannya'. Keluarga menyadari bahwa roh nenek moyang juga turut hadir dalam ritual tersebut, tetapi karena telah berbeda dunia, pihak keluarga tidak bisa menyampaikan secara langsung segala syukur, doa, dan harapan kepada wujud Tertinggi dan roh leluhur. Jadi, pelaku torok adalah jembatan bagi keluarga untuk menyampaikan segala syukur, doa, dan harapan. Penyampaian syukur dan doa kepada roh leluhur harus didasarkan pada kerendahan dan ketulusan hati yang diwujudkan melalui tuak.

Bertalian dengan itu, ritual legha kiwan merupakan ritual yang sakral mistis. Oleh karena itu, setiap peserta yang hadir harus terlibat sungguh-sungguh di dalam suasana sakral mistis, sehingga setiap peserta boleh mengalami sesuatu yang lain di dalam diri mereka. Pelaku torok dan peserta mengambil posisi duduk melingkar. Posisi duduk menyatakan kesopanan, penghormatan, dan kerendahan hati manusia di hadapan leluhur dan Tuhan Maha Pencipta. Robot (1996:15) menyatakan bahwa orang Manggarai mengenal dua jenis waktu, yaitu waktu rutinitas dan waktu mistis. Dalam waktu mistis, peserta ritus keluar dari waktu biasa, juga peserta ritus tenggelam dalam pengalaman mistis yang khusus, sekaligus mengambil jarak dengan dirinya sendiri sehingga terbuka untuk mengalami sesuatu yang transenden. Dengan demikian, ketika seseorang berada dalam ritual legha kiwan, dia berada dalam waktu mistis. Setiap peserta yang hadir mesti meninggalkan waktu rutinitas, sehingga terbuka untuk mengalami sesuatu yang transenden. Pelaksanaan ritual legha kiwan perlu terhindar dari sesuatu yang tidak baik. Sesuatu yang tidak baik berupa tanda-tanda seperti sadol 'kekeliruan' ketika mengungkapkan torok manuk dan torok ela. Kekeliruan dalam menyampaikan torok akan menyebabkan sakit atau kematian dalam keluarga yang melaksanakan legha kiwan atau kelas. Namun, agar terhindar dari resiko magis, sebelum melakukan torok manuk dan torok ela, pelaku torok memohon perlindungan kepada Mori agu ngaran ata dung agu dedek tana wan awing etan 'Tuhan maha pemilik yang menciptakan langit dan bumi' agar terhindar dari babang agu betang 'gangguan', seperti pada cuplikan berikut.

Denge lite mori agu ngaran ata dung agu dedek tana wa awang eta mori gho 'o ghami pande ai mbate dise ame redong dise empo apa ngasang legha de kiwan ghan woja landing wone mai ghan woja gho'o somong le rendut mata kemu lime ase kae de Lesak wone mai gho'o neka babang agu betang kamping ite Mori ngaran lawang pokot golo naga de tana toe mu'un kanan kepok. 
(Dengarlah engkau Tuhan dan pemilik yang menciptakan dan menjadikan tanah di bawah langit di atas Tuhan saat ini kami persembahkan karena warisan orang tua dan pesan leluhur yang namanya legha kiwan makan padi tetapi di dalam makan padi ini karena mata tertutup bersedekap tangan adik kakaknya kita Lesak di dalam ini jangan ada gangguan bersama engkau Tuhan pemilik sejak dijadikannya gunung penjaganya tanah bukan mulut saja ini tuak kepok)

\section{Konteks:}

Tuturan di atas diungkapkan oleh pelaku torok sebelum torok manuk dan torok ela dimulai dengan maksud memohon perlindungan dari Mori agu ngaran ata dung agu dedek tana wa awang eta 'Tuhan maha pencipta langit dan bumi' agar ritual legha kiwan dijauhkan dari babang agu betang 'gangguan'. Tuturan diungkapakan oleh pelaku torok sambil memegang sebotol tuak.

Dari uraian di atas dapat kita ketahui bahwa peran pelaku torok sangat penting. Pelaku torok adalah jembatan untuk berkomunikasi dengan leluhur. Tentu saja pelaku torok adalah orang yang mempunyai pengetahuan tentang torok dan berpengalaman melakukan torok. Dengan pengetahuan dan pengalaman itu pelaksanaan ritual legha kiwan terhindar dari resiko magis. Dengan demikian, ungkapan mu'un lujur lema emas 'mulut halus lidah emas' sangat tepat diberikan kepada pelaku torok yang bermakna kepandaian.

\section{Makna Pengharapan}

Pengharapan merupakan salah satu makna simbolis yang terdapat dalam ritual legha kiwan. Harapan merupakan keinginan supaya menjadi kenyataan. Harapan yang dipanjatkan kepada Tuhan dalam ritual legha kiwan adalah kope oles todo kongkol 'parang belit tumbuh bersatu' berarti saling mengikat dan bertumbuh bersama yang tentunya bermakna "persatuan". Ungkapan ini adalah sebuah nasihat agar manusia hidup dalam persatuan.

Bertalian dengan hal di atas, hewan persembahan dalam ritual legha kiwan adalah ayam dan babi, sehingga disebut torok manuk (torok ayam) dan torok ela (torok babi). Ayam yang dijadikan persembahan dalam ritual ini adalah manuk lalong cepang (ayam jantan bercorak). Namun, dalam konteks ritual leghwa kiwan, manuk lalong cepang dimaknai sebagai ayam jantan berwarna kuning padi dan jagung. Masyarakat setempat berharap kepada wujud tertinggi dan leluhur melalui manuk lalong cepang agar dapat menuai penenan berlimpah di musim tanam yang baru: padi menguning, jagung menguning dan berisi, kopi dan cengkih berbuah, dan sebagainya. Manuk dijadikan hewan persembahan karena bagi masyarakat Manggarai (Timur) manuk dikenal sebagai hewan yang rajin. Hal ini sejalan dengan penelitian Raru (2016), pemahaman budaya Manggarai menganggap ayam sebagai binatang paling rajin (berkokok manusia di pagi hari), toe toko wa tana 'tidak tidur di tanah', dan menjadi penjaga manusia (berkokok ketika ada setan yang lewat) (Raru, 2016). Harapannya adalah masyarakat dianugerahi semangat dan kerajinan dalam bekerja agar menuai panenan yang berlimpah. Makna pengharapan dapat dilihat secara jelas pada cuplikan data berikut:

Sa sua di'a urat manuk agu ela pe'an (semua yang hadir menjawab di'a) Denge lite mori ngaran itu wero torok molor wedus nggeluk ghami kamping ite Mori agu ngaran ai redong dise mbate dite gho'o nang torok molor wedus nggeluk ede wie gho'o salan torok molor wedis nggeluk ai rendut mata kemu lime ase kae ase kae de ghami mama embo Lesak wone mai hitu ga kap terus ngaraolon raza panden da'i de ghia ngasang wo nokong kira di'a wone mai gho'o gho de ngasang wie na'a wa kiwan manga teti kiwan weru neka betang agu babang ele meu embo Lesak wone mai wie gho'o ndong manuk wone mai manuk gho'o tegi kali ga kope oles todo kongkol ata sepa ata nggun wa leso sale neka timbang le ghau Lesak poli ndong manuk gho'o gami a ngasang toge de tenang ramba pele da'i ghau sakil agu ruda gho nang ndong manuk nang pe'an ela wone mai wie gho'o hitu gi torok gho'o manuk pe'an ela wone mai wie gho'o."

(Satu dua baik urat ayam di luar (semua orang yang hadir menjawab baik)

Dengar oleh Tuhan pemilik itu tadi doa kami kepada Tuhan dan pemilik karena turunan dan warisan dari leluhur ini doa baik kami malam 
ini jalan doa baik supaya diluruskan karena ngantuk mata kepal tangan adik atau kakaknya kami Lesak di dalam itu lancar terus ke depannya intensinya besok yaitu kebaikan di dalam ini namanya malam melepas tahun lama menyambut tahun baru jangan sahut oleh kamu leluhur Lesak pada malam ini pegang ayam dalam ayam ini permintaannya supaya dimusnahkannya ilmu jahat jangan kau pertimbangkan Lesak sudah pegang ayam ini supaya baik kau diselesaikan ini ayam dan di luar babi malam ini. Itulah doa ini ayam di luar babi pada malam ini).

\section{Konteks:}

Doa ini diucapakan oleh pelaku torok sambil memegang ayam sebagai hewan persembahan. Sementara itu, babi yang juga merupakan hewan persembahan diletakan di depan pintu rumah dengan keadaan pintu rumah terbuka. Selama torok berlangsung suasana sangat hening dan penuh rasa penghormatan.

Ritual legha kiwan adalah warisan dari leluhur yang harus dijalankan oleh masyarakat Manggarai Timur. Hal itu terbukti melalui ungkapan "mbate dise ame redong dise empo" yang berarti "warisan orang tua dan turunan dari leluhur". Oleh karena itu, masyarakat Manggarai Timur wajib melaksanakan ritual ini tiap tahun. Berkaitan dengan kelas, seperti yang telah diuraikan sebelumnya bahwa ritual legha kiwan adalah salah satu prasyarat kelas. Apabila ritual legha kiwan tidak dilaksanakan, maka kelas yang akan dilaksanakan tidak diterima oleh leluhur.

Segala harapan disampaikan kepada Mori agu ngaran ata dung agu dedek tana wa awang eta 'Tuhan yang menciptakan dan menjadikan langit dan bumi' melalui ritual legha kiwan, secara khusus kelancaran acara kelas yang akan dilaksanakan, yang terbukti pada kutipan doa wone mai hitu ga kap terus ngaraolon raza panden da'i de ghia ngasang wo nokong kira di'a 'di dalam itu lancar terus ke depannya intensinya besok yaitu kebaikan'. Masyarakat Manggarai meyakini apabila ritus kelas belum dilaksanakan, maka jiwa/roh dari orang yang meninggal belum disucikan atau diselamatkan.

Torok diawali dan diakhiri dengan seruan oleh pelaku torok "dia urat manuk agu ela" secara harafiah berarti 'baik/bagus usus ayam dan babi', kemudian dijawab oleh semua orang yang hadir "di'a" yang berarti 'baik/bagus'. Kebaikan atau keburukan di hari-hari yang akan datang dapat diramal melalui urat manuk atau usus ayam yang dijadikan persembahan. Kemudian, puncak ritual legha kiwan ditandai dengan penyembelihan hewan kurban berupa ayam dan babi. Apabila ayam dan babi telah disembeli, maka ritual legha kiwan pun selesai. Ayam jantan atau babi jantan selalu dijadikan hewan persembahan dalam ritual adat apapun, karena bagi masyarakat Manggarai (Timur), "jantan" melambangkan keperkasaan dan keuletan. "Jantan" merujuk pada jati diri seorang laki-laki sebagai penggerak utama dalam bekerja (mengolah kebun). Ayam dan babi dalam ritual legha kiwan bermakna pengharapan. Harapannya adalah dianugerahi semangat, kerajinan, dan kekuatan dalam bekerja agar menuai panenan yang berlimpah. Kaitannya dengan ungkapan kope oles todo kongkol 'persatuan', yakni segala pekerjaan akan diselesaikan dengan baik apabila dilakukan bersama-sama. Masyarakat harus saling bahu-membahu dalam menyelesaikan perkerjaan di ladang.

\section{SIMPULAN}

Berdasarkan uraian pada bagian hasil dan pembahasan disimpulkan bahwa ritual legha kiwan dalam ritus kelas bermakna simbolis penghormatan, kerja keras, cinta kasih, kepandaian, dan pengaharapan. Makna-makna itu terkandung dalam simbol-simbol, baik berwujud tuturan-tuturan lisan, objek fisik, dan tindakan. Makna-makna tersebut tidak terlepas dari konteks sosial dan budaya masyarakat Manggarai Timur.

Kajian mengenai wujud dan makna simbolis ritual legha kiwan ini tidak luput dari kekurangan atau kelemahan. Oleh karena itu, ada beberapa keterbatasan dalam penelitian ini, yaitu (1) sebagian data belum dianalisis secara mendalam akibat keterbatasan sumber; dan (2) sebagian data belum diterjemah secara gamblang ke dalam bahasa Indonesia, sehingga analisis tidak mendalam. Berangkat dari keterbatasan yang ada, peneliti berjanji untuk menutup kelemahan pada penelitian yang lain. Selain itu, peneliti menyarankan kepada peneliti lain agar melakukan penelitian serupa dengan fokus yang serupa guna mendapat 
gambaran yang spesifik dan signifikan mengenai wujud simbol dan makna simbolis dalam ritual legha kiwan.

\section{DAFTAR PUSTAKA}

Ahmadi, D. (2005). Interaksi Simbolik: Suatu Pengantar.

https://ejournal.unisba.ac.id/index.php/m ediator/article/view/1115

Creswell, J. W. (2010). Research Design: Pendekatan Kualitatif, Kuantitatif, dan Mixed. Pustaka Pelajar.

Danesi, M. (2004). Messages, Sign, and Meaning: A Basic Textbook in Semiotics in Communication Theory. Canadian Scholars Press Inc.

Deki, T. K. (2011). Tradisi Lisan Orang Manggarai. Parrhesia Institute.

Eco, U. (1984). Semiotic and The Philosophi of Language. The Macmillan Press LTD.

Foley, W. (1997). Anthropological Linguistic: An Introduction. Basil Blackwell.

Kamus Besar Bahasa Indonesia. (2019). kbbi.kemdikbud.go.id/entri/religius

Lemon, K. (2003). Symbolic Meaning of Brands/Product A Symbolic Interactionism Perspective. Texas Tech University.

Mahsun. (2012). Metode Penelitian Bahasa. Rajagrafindo Persada.

PDSPK. (2016). Analisis Kearifan Lokal Ditinjau Dari Keragaman Budaya. PDSPK Kemdikbud RI.
Pranowo. (2014). Teori Belajar Bahasa. Pustaka Pelajar.

Pranowo dan Neneng Tia. (2019). Wujud Dan Makna Pragmatik Bahasa Nonverbal Dalam Komunikasi Masyarakat Jawa. Linguistik Indonesia, 37(2), 169-184. https://doi.org/10.26499/li.v37i2.111

Rahardi, R. K. (2009). Bahasa Previor Budaya. Pinus Book Publisher.

Raru, G. (2016). Tuturan ritual. https://doi.org/10.17510/paradigma.v6i1. 79.ABSTRACT

Riley, P. (2007). Language, Culture and Identity: An Etnolinguistic Prespective. Continuum.

Robot, Marsel, \& Dkk. (1996). Kajian Tola Kaba Sastra Lisan Manggarai. Pusat Pengembangan dan Pembinaan Bahasa.

Song, L. (2010). The Role of Context in Discourse Analysis. Journal of Language Teaching and Research, 1(6), 876-879. https://doi.org/10.4304/jltr.1.6.876-879

Sudaryanto. (2015). Metode dan Teknik Analisis Bahasa. Sanata Dharma University Press.

Yule, G. (2014). Pragmatik. Pustaka Pelajar.

Zhirenov, S. A., Satemirova, D. A., Ibraeva, A. D., \&, \& Tanzharikova, A. V. (2016). The cognitive content of the world of symbols in a language. International Journal of Environmental and Science Education, 11(9), 2841-2849. https://doi.org/10.12973/ijese.2016.725a 